This item was submitted to Loughborough's Research Repository by the author.

Items in Figshare are protected by copyright, with all rights reserved, unless otherwise indicated.

\title{
Opportunity and opportunism: The expatriation practices of Indian information technology multinational corporations
}

PLEASE CITE THE PUBLISHED VERSION

http://dx.doi.org/10.1016/j.intman.2016.11.001

PUBLISHER

(C) Elsevier

VERSION

AM (Accepted Manuscript)

\section{PUBLISHER STATEMENT}

This work is made available according to the conditions of the Creative Commons Attribution-NonCommercialNoDerivatives 4.0 International (CC BY-NC-ND 4.0) licence. Full details of this licence are available at: https://creativecommons.org/licenses/by-nc-nd/4.0/

\section{LICENCE}

CC BY-NC-ND 4.0

\section{REPOSITORY RECORD}

Shah, Dhara, Bob Russell, and Adrian Wilkinson. 2019. "Opportunity and Opportunism: The Expatriation Practices of Indian Information Technology Multinational Corporations". figshare. https://hdl.handle.net/2134/26173. 


\section{Opportunity and Opportunism: The Expatriation Practices of Indian Information Technology Multinational Corporations}

\section{Dhara Shah *}

Lecturer, Department of International Business and Asian Studies

Griffith Business School, Griffith University

170 Kessels Road, Nathan, QLD 4111, Australia

Email: d.shah@griffith.edu.au

Bob Russell

Adjunct Academic

Griffith Business School, Griffith University

170 Kessels Road, Nathan, QLD 4111, Australia

Email: bob.russell@griffith.edu.au

Adrian Wilkinson

Director, Centre for Work, Organisation and Wellbeing

Griffith Business School, Griffith University

170 Kessels Road, Nathan Campus, QLD 4111, Australia

Email: Adrian.Wilkinson@griffith.edu.au 


\begin{abstract}
Although effective International Human Resource Management during an international assignment constitutes a significant factor in ensuring success of an expatriate assignment, there has not been much research that studies the expatriation practices associated with the global delivery model that has come to be identified with global outsourcing. The purpose of this paper is to understand the expatriation practices of Emerging Market Multinational Corporations (EMNCs) in the Indian IT sector, by examining the experiences of Indian IT workers sent to work on international client projects in a western country. We have used qualitative semi-structured interviews with 47 Indian IT expatriates from Indian IT MNCs working at client sites in Australia. We find that there is inadequate attention paid to expatriation both prior to emigration and while workers are overseas and employed at client sites. Such human resource shortcomings may be inherent in the global delivery model that is an important feature of Indian IT business. The implications of these findings are discussed in the paper.
\end{abstract}

Key Words: IT workers; Indian IT MNCs; global delivery model; IHRM; expatriate adjustment

\title{
1. Introduction
}


Indian software companies have received considerable global attention specifically within the Information Technology (IT) services sector (Birur and Muthiah, 2012; Mathew et al., 2012). Since the early 2000s concepts like Global Value Chain (GVC) and Global Production Network (GPN), used to understand the international expansion and geographical fragmentations of the supply chain, have gained a lot of popularity (Gereffi 2001). Although these concepts were developed for the manufacturing industry, researchers have argued their usefulness and adaptability to the service sector (Feuerstein, 2013; Selwyn, 2013). The practice of onsite and offshore model also known as the Global Delivery Model (GDM) of IT MNCs developed in a similar fashion, with potential cost savings for both labor and resources (Manning et al., 2015). This practice entailed Indian IT professionals being sent to work at client sites thereby facilitating and negotiating information with teams based in India (Sirmon et al., 2008). The model has seen rapid growth due to the strategic business savings for companies in international markets (Agrawal et al., 2012; Russell, 2009; Sudhakar et al., 2011). The present study examines this special type of skilled labor flow, originating with indigenous MNCs from an emerging economy — in this case India — and witnessing international assignments of shorter or longer duration being carried out onsite for clients who are located in the developed world.

The rise of IT production marks a new era, fundamentally restructuring the way work is organized and controlled by intensifying the standardization and fragmentation of products and services (Feuerstein, 2013; Flecker and Meil, 2010). Thus it is important to understand the expatriation practices of Indian IT MNCs in the context of onsite-offshore outsourcing relationships. Sending a software consultant to an overseas onsite location for work can cost an IT MNC approximately four to five times as much as conducting the work from India (Vallabh et al., 2008). To take just one example, the turnover of IT expatriates can delay client project completion, increase costs and jeopardize overall quality (Jiang and Klien, 
2002). The high growth rate of the Indian IT industry, estimated for FY2015 as USD 146 billion (NASSCOM, 2015) and the huge number of software professionals - approximately 1.2 million for FY2015 working as export employees (NASSCOM, 2015) - are the major motivating factors for this study. While much has been written about IT professionals working in India, the significant experiences of Indian IT expatriates at a client site within the larger scope of international human resource management (IHRM) has largely been ignored. The challenges Indian IT expatriates encounter during an international assignment at client locations, trying to juggle living and working in a new environment, are worthy of investigation. Varma and Budhwar (2012), in their introduction to the special issue on IHRM in the Indian context, noted that Indian HRM systems continue to be somewhat unstructured and less formal compared to western models. Equally, there is a lack of empirical research to help us understand the Indian IHRM function.

To address this gap in the literature a major contribution of this research is an understanding of the IHRM, in particular the expatriation practices of Indian IT MNCs, based on the GDM, and their impact on the experiences of IT expatriates at client sites in a developed country. Moreover, this study will explore and broaden Black and colleagues (1991)'s framework for expatriate adjustment and its relevance to include this cohort within the GDM. The research will provide empirical data that will increase both the practical and theoretical understanding of the adjustment experiences of Indian IT expatriates in Australia, drawing on Perceived Organizational Support Theory (POS). This theory provides researchers with the means to understand the experiences of IT expatriates based on the IHRM expatriation practices of MNCs that govern the behavior of expatriates at the client site. To this end, this research serves to extend the existing IHRM literature by focusing on a relatively new expatriation experience that originates with MNCs that are headquartered in the developing world and with highly skilled employees who find themselves "leased" out to 
client firms at the centre of the global economy. In addition, the findings of the study are relevant for other fast growing industries in India and other developing countries. Interview data from the Indian IT expatriates who stayed on the assignment will reveal their perceptions of the impact of the IT business model (GDM) on their international work assignments.

\section{Theoretical background}

\subsection{Indian IT Global Delivery Model and HRM}

Overall, much has been written about the history and growth of the Indian IT industry and outsourcing (Agrawal and Thite, 2006; Bhatnagar and Madon, 1997; Nanda and Khanna, 2010; Sharma and Loh, 2009; Vallabh et al., 2008). Some researchers (Bhatnagar and Madon, 1997; Nanda and Khanna, 2010; Sharma and Loh, 2009), for example, have looked at emerging trends in the outsourcing of IT services and leveraging for higher value activities, while Vallabh and colleagues (2008) have evaluated the financial cost structure of the onsiteoffshore model, and Agrawal and Thite (2003) and Thite and colleagues (2014) have identified some of the human resource issues and challenges in the Indian software industry. Until the 1990s, the concept of spatial relocation of work overseas was exclusively centered on manufacturing industries; it was only with changes in technology and work organization that service work became tradable (Feuerstein, 2013). The development of global sourcing of business processes in the 1990s within the service industry in India (Manning et al., 2008) began with the ICT sector capitalizing on the availability of a large low-cost pool of skilled and English-speaking IT professionals (Feuerstein, 2013), as well as exploiting labor arbitrage effects (Manning et al., 2008). Compared to an earlier era when people were sent to clients as a means of body-shopping and client set-up offshore locations, many MNCs headquartered in India are now providing specialized services to clients around the globe 
(Sirmon et al., 2008). One of the drivers of these changes has been the challenge and complexity involved in managing global outsourcing and the establishment of global delivery models (GDM) by IT MNCs (Manning et al., 2015).

Within the GDM, international clients send their work offshore to low-cost countries like India. While part of the work gets done at offshore locations, a number of members from the project team are sent onsite to client locations to work with the client, define project requirements, coordinate with the offshore team and also attempt to secure more business from the clients (Agrawal et al., 2012; Upadhya and Vasavi, 2006; Woodard and Sherman, 2015). GDM has been known to have significantly contributed to the cost effectiveness for the Indian IT MNCs. Doh (2005) argues that the growth of offshore outsourcing is not purely based on cost motivations but rather on more value added and the strategic deployment of labor. This has meant that there is a shift in the balance of power in global strategy, leading many Indian MNCs to develop their global capabilities (Levy, 2005). In particular, the commoditization of IT workers and growing competition for global client projects (Manning et al., 2008) has meant that the role of HR within the Indian IT MNCs is more of a strategic partner rather than an employee advocate. One of the major challenges facing MNCs from India is the shortage of suitably qualified personnel (Budhwar, 2004) to be sent to work at international locations (Collings and Scullion, 2006). Moreover, the IT workers sent to client sites have a critical role to play as they have to work effectively within a new host location and a new organization. If their assignment fails, substantial financial as well as reputational costs are involved for them and their employing IT organizations. This brings IHRM challenges for the Indian IT MNCs.

The limited research conducted on Indian IT industry to date (Agrawal et al., 2012; Lakha, 2009; Mathew et al., 2012; Thite et al., 2014; Thite et al., 2012; Upadhya and Vasavi, 2006) suggests that HR systems and practices in the software industry in India are perceived 
as being inadequate by IT workers, due to the unique structure and rapid growth of the Indian IT sector. For most Indian IT workers, an international assignment is an incentive for working in an IT industry, especially the notion of working in a developed country. Agrawal and colleagues (2012) raise some important issues related to the onsite-offshore model namely, deficient technical and interpersonal skills among team members and the offshore team's perceptions of a lack of planning that makes project delivery tasks more complex (Agrawal et al., 2012). While the authors point to important issues related to the onsiteoffshore model their study is focused on HR practices in India, not on IT workers at client sites (see also Budhwar and colleagues, 1997, 2001, 2002, 2006). Furthermore, Flecker and Meil (2010) identify the issues that emerge when many clients create competition among IT companies by being very demanding. Upadhya (2009) further asserts that to keep their cost estimates down when bidding for a client project, Indian IT companies often underestimate the man-days required for a project which results in long working hours for employees. This may raise many labor-related issues ranging from compensation to workers' rights and conditions, especially when they are sent to work at client locations. This in turn brings further challenges for the Indian IHRM function which is already facing competitive pressures while managing a global workforce (Agrawal et al., 2012; Thite et al., 2012; Varma and Budhwar, 2012). Thus the expatriation of Indian IT workers is an important topic to explore.

Global offshoring and outsourcing have many implications for IHRM research, while presenting unique challenges for the MNCs and their HR function (Morley and Collings, 2004). Within the topic of IHRM, international assignments and expatriation management issues have dominated the research agenda. Scullion et al. (2007) point out that the emergence of countries like India and China has changed the spatial landscape of international business and the nature of international assignments, emphasizing the need for 
scholars in the IHRM field to explore new ideas through innovative theoretical and methodological approaches. The current study shows the dynamics involved in sending IT workers to client sites on temporary assignments that may vary from months to years, where expectations involving both work and other aspects of the host client location may be quite different to those in the society of origin. The impact of the GDM on Indian IHRM, specifically on the preparation and ongoing support for IT expatriates sent to overseas client sites, is the main focus of this paper.

\subsection{International adjustment framework and Perceived Organizational Support (POS) theory}

This study uses Black et al.'s (1991) adjustment model to assess its applicability for the Indian IT expatriates at client sites within the GDM. Black and colleagues (1991) developed a framework for understanding international adjustment by combining the literature on domestic and international relocation. They conceptualize adjustment in two phases: anticipatory and in-country, which is helpful in understanding an expatriate's adjustment experiences prior to and during the assignment. Within the anticipatory phase, pre-departure preparation, previous international experience and an organization's selection mechanisms are important for individuals to have accurate expectations, which provide a basis for anticipatory adjustment for expatriates. Black and colleagues (1991) argue that pre-departure preparation correlates positively to accurate expectations and adjustment in the new environment. Their research has triggered further studies as well as two meta-analyses (Bhaskar-Shrinivas et al., 2005; Haslberger et al., 2014; Hechanova et al., 2003; Strubler et al., 2011). Black and colleagues further argue that individual efficacy along with organizations' socialization and support practices have a positive relationship to the degree of adjustment. This framework has been used in many international adjustment studies of traditional managerial expatriates sent to a subsidiary operation (Bhaskar-Shrinivas et al., 
2005). However, Black et al.'s (1991) model in its current form is restrictive with regards to exploring the IHRM practices within the low-cost GDM, particularly pre-departure preparation and in-country support practices of the parent Indian MNC for IT expatriates working at client organizations.

There has been extensive literature highlighting the importance for organizations to prepare employees for overseas sojourns as well as ongoing in-country organizational support (Bhaskar-Srinivas et al., 2005; Gupta et al., 2013; Guzzo et al., 1994). Expatriates formulate their own expectations of the host country prior to leaving for the assignment (Reiche et al., 2011). In the case of a lack of accurate information, the expatriate may stereotype the host culture with their own experience and perceptions of their own culture. Moreover, expatriates' perceptions of supportive organizational practices have been identified with positive adjustment in the host country (Kraimer et al., 2001; Shaffer et al., 1999; Wang and Takeuchi, 2007).

Eisenberger and colleagues (1986) developed an organizational support theory with a central concept of POS; it is one of the most frequently cited theories for employeeorganization relationships (Eisenberger et al., 2001; Kahumuza and Schlechter, 2008; Kraimer et al., 2001; Maertz et al., 2007). POS refers to the perceptions of the extent to which employees are valued and their wellbeing is cared for by their organization (Eisenberger et al., 1986). Compared to earlier studies, which focused on organizational support as an overall function (Black et al., 1991; Caligiuri et al., 1998; Shaffer et al., 1999), later studies have adopted a multifocal view of organizational support - for example, adjustment, financial and career (Kraimer et al., 2001; Kraimer and Wayne, 2004; Takeuchi et al., 2009). Caligiuri and colleagues (2001) point out that expatriates should have realistic expectations before their international assignment, which will help in how they perceive their psychological contract with their organization. Guzzo et al. (1994) maintain that a 
psychological contract between the organization and the expatriates can be evidenced within POS. Kawai and Strange (2014) further argue that POS is positively related to work adjustment in the host country. Limited research focusing on this relationship has identified organizations providing language and cross-cultural training, relocation assistance, support for finding schools for children, housing and legal issues as having a positive impact on expatriates' adjustment in the host country (Kawai and Strange, 2014; Wu and Ang, 2011). The current study will draw on POS theory to identify the kind of expectations that the Indian IT expatriates have of the support from their parent and/or client organizations and its impact on their experiences at the host location.

Thite and colleagues (2014) identified that Indian HR faces many challenges with regards to internationalization, which as noted by Upadhya (2009) relate to the remote management and modes of control adopted by Indian IT MNCs over their global Indian IT workforce. Thus it becomes significant to understand whether Black et al.'s (1991) framework and POS theory, with their embedded assumptions of adjustment as a broad multifaceted construct with strong relationships to parent organizational support practices, can be applicable in the context of Indian IT expatriates sent to client sites within the onsiteoffshore relationships of GDM.

\section{Methodology}

Due to the relative dearth of research on Indian IT expatriates who find themselves in an onsite-offshore work relationship within the GDM of Indian IT MNCs, this study has adopted an exploratory approach through the use of qualitative methodology (Eisenhardt, 1989). Since the objective of the present research was to understand the perspectives of IT expatriates on the IHRM practices of Indian IT MNCs and their impact on their adjustment experiences, the chosen epistemology needed to be suited to such an inquiry and provide a 
perspective that is useful in making sense of such a phenomenon (Crotty, 1998). This research has explored the phenomenon of adjustment in terms of how Indian IT expatriates have described and explained the expatriation practices of their organizations and their perceptions of preparation and in-country support in relation to their adjustment in the host country (Eisenhardt, 1989). Our aim has been to capture the actual voices of this specific cohort, working at an offshore client site. Given the nature of our subject matter — the work life experiences of onsite IT expatriates and associated IHRM practices at the client site we employed a snowball sampling technique where the first author contacted a small number of members within the target population and got them to introduce others (Walliman, 2006). All the respondents were the ones who had stayed on the assignment; individuals who might have left due to the issues raised are not part of the study. The data collection was conducted in three Australian cities (Sydney, Melbourne and Brisbane) during 2009. Semi-structured face-to-face interviews were conducted by the first author with 47 Indian IT workers working for five Indian IT MNCs; this process allowed for in-depth probing during each interview (Denzin and Lincoln, 2011).

Interviewees had been on the assignment for a few months up to two years and were between the ages of 25 and 40 years with an average age of 30 years. Of the 47 expatriates interviewed only seven were females. The five Indian IT MNCs that were chosen were among the medium to large Indian IT consulting and IT services companies, each with a turnover ranging from over $\$ 40$ million to $\$ 1.5$ billion dollars (US) and employing from 10,000 to 50,000 employees. The interview guide (see Table 1) was developed following Black et al.'s (1991) model and POS theory and it consisted of open-ended questions about their international assignment expectations and experiences related to preparation and organizational support practices of their parent Indian MNC. Interviews ranged from 40 minutes to one and half hours in length with an average of approximately one hour per 
session. Each interview was tape-recorded after gaining participant consent, and each recording was transcribed verbatim.

\section{Insert Table 1 here}

Two phases of analysis took place: a content-coding approach followed by a thematic approach. Patton $(2002,432)$ states that qualitative analysis involves "reducing the volume of raw information, sifting trivia from significance, identifying significant patterns and constructing a framework for communicating the essence of what the data reveal". Within the first phase of organizing the data, interviews were transcribed by the first author. The transcripts were read through repeatedly and during these readings, the first author made notes on important points, overall impressions and emergent ideas (Ritchie and Lewis, 2003), making sense of them within the context of what the interviewee says. This process helped in familiarizing the first author with the data, and the emerging main themes and patterns were then categorized (Ritchie and Lewis, 2003). As the current study was based on Black et al.'s (1991) framework and POS theory, the process began with a deductive approach. Initially, codes were assigned to the data and were then reviewed to ensure that all appropriate responses were coded accurately (Witte and Witte, 2004). The initial themes that were identified were pre-departure training, anticipatory adjustment and organizational support practices that impact on their overall adjustment in the host country. The transcripts were entered into Nvivo software, which helped in the organization of the data, while enhancing the reliability of the study (Richards, 2009). NVivo (v. 8) computer software was used to develop and collate different themes and facilitate data management, which allows the investigator to work efficiently with complex coding schemes derived from a large body of transcripts, and facilitates analytical depth and complexity (Bazeley and Richards, 2000).

After this phase, the researcher strived to look at the data afresh for undiscovered 
patterns and emergent understandings (inductive analysis) (Patton, 2002). Constant comparisons of the data helped in further ensuring the rigor of the study. Variations within the interviews were also sought in regards to participants' demographic characteristics, location of the expatriates and parent IT MNCs. Further undiscovered patterns and themes that emerged from the data analysis were client-centricity, time to prepare, the low-cost nature of GDM, organizational support, accommodation and parent HR support in the host country (as discussed in the next section). The first author's cultural background made her sensitive to the participants' experiences and further enhanced sense-making of the data collected (Patton, 2008). Moreover, it was found that the participants were pleased to share their stories and provide insight into their experiences, which triggered new revelations of their experiences on the assignment.

Within qualitative research, data collection and analysis may be influenced by the biases of the researcher. These biases could be due to the objectives of the data collection; personal biases and experiences; or stress or discomfort experienced by the participants or researcher due to the research process. Wolcott (1999) points out that any of these factors could potentially impact on the behavior or field notes during data collection. The first author has ensured the study's rigor by identifying the reactive effects on data collection, maintaining a reflexive journal and field notes, using memorandums and reviewing the themes with the two co-authors.

\section{Findings}

The findings of the study are presented in terms of the themes and sub-themes that emerged during the final stage of data analysis. It was important to understand whether IT expatriates experiences within the globalizing Indian IT industry with the dynamic interplay between GVC and GDM fit into the expectations of Black et al.'s (1991) framework and POS 
theory. The IT expatriates are referred to by pseudonyms with the code for the MNC they were working with $(\mathrm{A}, \mathrm{B}, \mathrm{C}, \mathrm{D}$, and $\mathrm{E})$. This section is divided into two main themes with sub-themes. The first main theme identified is the "client-centric model" which includes two sub-themes of "time to prepare" and "preparation and anticipatory adjustment" and the second main theme is "low-cost nature of the GDM and organization support", with subthemes of "accommodation in the host country" and "parent HR support in the host country and intention to stay or leave". These are presented below.

\subsection{Client-centric model}

A central theme that emerged from the interviews was that the IT industry was seen as being client-centric; rigidly controlled and dictated by the client. Within this main theme the two sub-themes that were prominent were "time to prepare" and its impact on "preparation and anticipatory adjustment”. To keep with Black et al.’s (1991) framework and POS theory arguments, the respondents were first asked about their preparation for the assignment. Interestingly the time between notification of the assignment and the actual departure was identified to have a lot of bearing on the Indian IT expatriates' adjustment in the host country. Moreover, due to lack of time, most of them felt that they had not anticipated many issues that they faced during the assignment. While Black and colleagues (1991) argue that training prior to the assignment helps with the anticipatory adjustment, they — like most studies on preparation of the expatriates - assume that expatriates would have enough time prior to the assignment to prepare. However, within our respondent group working within the realms of global outsourcing model and client-dependency, time prior to the assignment was identified as a critical sub-theme that impacted on the preparation of IT expatriates, as discussed in the next section.

\subsubsection{Time to prepare}


One of the main findings of this study is that due to the client-controlled and clientinitiated nature of IT assignments, the respondents recognized that their parent Indian IT companies had little control over when they (IT workers) had to leave for the assignment. Indeed approximately 40 percent of the respondents said they had less than one week to prepare for the assignment and that this (not surprisingly) effected their ability to undertake adequate preparation. One interviewee stated that he was given:

One week, as it was an urgent requirement and the project had to be picked up, so I had to come in a week's time, so I did not get much time in India (Rakesh/E).

Consequently, this individual was unable to attend any pre-departure training and this was thought to bear upon his subsequent adjustment during the initial days in the host country as well as his negative perceptions of the support he received from his parent organization. Another respondent who was given just one day to pack his bags and leave stated:

I had to do my shopping till $11.00 \mathrm{pm}$ and getting my currency done and flight tickets, it's a bit hard ... I could not visit my parents, either, as they live far. It would have been good if I had enough time. My visas were ready, they said I may be going but they did not have any project for me, so they relocated me from Hyderabad to Bangalore to a completely different project and client and when this requirement came, they called me, as I had the visa and my experience in that area (Mitesh/A).

This respondent explained how traumatic it was for him to travel within a day with all of the implications of travel arrangements and the arrival to the host country. Although the visas were ready, there had been no overseas projects for him; and with the huge pressures and long working hours of his job, he had not begun any preparation for working and living abroad. The above two quotes reflect the experiences of many other respondents who also recounted similarly stressful experiences related to limited time to prepare prior to their 
assignment. Respondents indicated that these issues along with the inadequate and deficient planning and management of Indian IT MNCs caused them to move between cities, countries and projects within a short period of time.

On the other hand, almost 30 percent of the participants who had more than three weeks to prepare perceived this to be an adequate amount of time. It could be that due to their age group (between 25 and 35 years), and their marital status (single or young couples or young families), and the nature of IT work, they were more often mentally prepared to go on an international assignment at some point in their careers and for most this was a big opportunity to go to international client sites. As one of the single expatriates — who had around 20 days in which to prepare - commented:

I felt that it was good enough time for me to prepare for the assignment, get everything organized and learn about the work that was expected and get all the necessary training and other things organized (Rahul/D).

Time to prepare has a significant impact on how an expatriate mentally prepares for the assignment and the host country expectations they perceive, therefore it is no surprise that the present study found that lack of time prior to the assignment impacted on the overall preparation of the Indian IT expatriates, and on their adjustment in the host country. This time pressure was attributed to the client-centric GDM, emphasized by low-cost demands and rising competition. This, in addition to the lack of control over when the IT workers need to be sent to client sites, impacted on Indian IT MNCs IHRM planning. Furthermore, this lack of time meant that the expatriates were not prepared for the host country, leading to lack of foreknowledge of the issues they encountered.

\subsubsection{Preparation and anticipatory adjustment}


Many participants reported seeing an international project as a dream opportunity. They did not foresee any fundamental obstacles as they spoke English and many were already working for the same client projects in India. Most admitted they did not expect a great deal from their parent organization with regards to support in the host country. Moreover, in our cases pre-departure preparation provided by the organization was often overlooked or deficient. More than half of the respondents indicated that there was little focus on preparing them for their allocated host. Technical concerns were paramount, so that if there was a particular requirement by the client, then an available person with the required technical skill set was sent on the assignment. Of the ones who were provided training 50 percent said it was either irrelevant or inadequate. One respondent revealed the extent of the training she was given:

There was a bit of training but not exactly; in the training, I was given documents to read and I just prepared those documents before moving... (Aarti/A).

Lack of effective cross-cultural training programs adds to the probability of expatriate failure or poor performance on the assignment (Caligiuri et al., 2001; Gupta et al., 2013; Tung, 1987).

One respondent stated:

You do get trained in most of the things, how to react and how to behave, so you do get that type of training and specific to the country and also things like what would people expect? We have two or three days of program. They give you a description of how to interact with the client... I think they could have done better, they give you all the business side but how to cope there... the climatic conditions here, you are not prepared. It was a pretty bad experience for me outside work. (Rihaan/D) 
Another expatriate noted: "Yes, I received (training) but there is a lot of scope for improvement. The training was very poor — you can say it was zero". (Aman/C)

There is a general lack of preparation for expatriates amongst most organizations, however in our research this factor was emphasized by the lack of time and the low-cost client-dependent nature of Indian IT industry. The lack of preparation further influenced IT workers' anticipatory adjustment in relation to host country and work expectations (Black et al., 1991), which impacted on their overall adjustment in the country.

This industry structure, as noted above, is associated with deficient and often ad hoc planning. Given the volatile nature of the work, people can be thrown from one assignment to another and sent on international projects based on their availability at extremely short notice. According to many of our interviewees these dynamics lead to limited time for preparation in the case of international assignments. Due to huge work pressures many participants had either not attended the training session or found it lacking, due to which they were unable to anticipate the issues they faced on the assignment. Next we discuss our second main theme of "low-cost nature of GDM and organization support".

\subsection{Low-cost nature of GDM and organization support}

Researchers have pointed to the importance of ongoing organizational support based on POS theory and the perception of such support in temporary professional labor migration (Birur and Muthia, 2012; Kraimer et al., 2001). It is argued here that resources and assistance provided by the organization to the expatriates when they reach the country of assignment has a significant bearing on their overall adjustment and their commitment to that organization. In our study, participants implied that the labor arbitrage effects of the IT industry meant that to keep their costs down and stay competitive, the IT MNCs expected them (IT expatriates) to commence client projects within a couple of days after arrival into 
the host locations. Thus it was important to understand how the expatriates in the present study perceived the organizational support they received from their parent employer while overseas, and the influence this had on both their adjustment process and their intention to remain with or leave the organization.

\subsubsection{Accommodation in the host country}

There was a common theme among the participants of our study in regards to a lack of basic assistance offered by the Indian companies in the arrangement of suitable accommodation. Some respondents explained that the organization provided them with a budget to look for accommodation for a week, but it was left up to them to find adequate housing in off-work hours.

No they do not [book any accommodation], they just reimburse you but they do not provide any accommodation. I knew some colleagues who helped, actually. But if someone does not know anyone, there will be a problem, the company does not do anything in that situation, and they expect that people are mature enough to get into a hotel accommodation for the first five days. (Arun/B)

Even though organizations did reimburse employees for their initial hotel accommodation, our interviewees pointed out that travelling outside their country for the first time and lack of time to prepare was a daunting experience for them. Some interviewees revealed that although they now felt adjusted to the host country, it had taken them a long time and they were disappointed at the way they were "dumped" in Australia. Regardless, for many it was still better to earn dollars and be able to save and send money back home rather than returning to India. Furthermore, many had intentions of applying for permanent residency, which gave them a reason to stay on in the assignment. 
Lack of accommodation during the initial days had a significant bearing on the expatriate workers, as they had to deal with not only the stress of encountering a new country and a new work environment, but also this added pressure. For example, one respondent reported that he had only one weekend to search for a house without any assistance from his employing organization. Some respondents reported that they had contacted their colleagues already on the same assignment and asked them to arrange accommodation and some others stayed with friends or family in the host country. A few who did not have contacts in Australia had booked a hotel prior to leaving for the assignment, without comprehending the distance from their workplace to the hotel. For some that had meant long distance travel and lack of time to look for other accommodation. International assignments can create a great deal of uncertainty within the new work environment and general culture, which in turn can cause considerable stress among expatriates. Researchers (Ashford and Taylor, 1990; Fisher, 1985; Gregersen and Black, 1990) have long recognized the role of social support for individuals in a new environment in reducing the uncertainty caused by novel situations. There were suggestions from the respondents that they need better basic support from the organization and time to look for accommodation, to get a feel for the place before they begin work. One of the recently arrived respondents exclaimed:

Another thing is about accommodation: our company provides us with one week's accommodation - I want to know if there is any possibility of getting accommodation in a week's time in Melbourne; moreover, we are expatriates, we are less trusted as compared to the Australian citizen and PR (permanent resident). No, we do not get [time to look for accommodation], the day we come here, we have to start work the next day, I usually travel on Fridays, so I have the weekend off and start on Monday morning. (Aaditya/B)

As pointed out by the respondent and many others during the interviews, workers do not get any time after arriving in the host country to acclimatize or look for accommodation, as 
they usually start work within a day or two after their arrival. This results in further challenges, especially for the ones who did not have time to prepare prior to their assignments, leading to many perceiving their parent organization to have violated the psychological contract. In cities like Sydney and Melbourne, respondents expressed concerns over difficulty in finding accommodation within limited periods of time, especially for contractors without a rental history in Australia. As one respondent explains, the poor management by their IT MNCs contributed to their issues related to overwork:

Project management within my company is very task-oriented, it's not really managed but more controlled; it's more reactive rather than proactive. So that kind of planning out could be improved a lot...There is a lot of room for improvement. Effort that can be put in could be improved and there is a big scope to do that. (Tejas/B)

Most of the participants blamed poor planning of their Indian company along with intense competition for the long hours they were required to work. Another expatriate explained how the issues of poor planning meant huge work pressures. He explains:

They need to plan properly... we are facing issues, it's because of planning, it's like how many days it will take to complete a project, they will say 30 days and it will take 45 days... so you have to work for the extra 15 days and we have to adjust that work in the specific days of time... (Ashish/A)

These circumstances added to the challenge of finding accommodation in the host society. Overall there was scant organizational support for accommodation. This absence of support caused further stress, especially during the initial days. Compared to earlier studies, (Kawai and Strange, 2014; Wu and Ang, 2011), where expatriates' POS and positive adjustment in the host country was related to cross-cultural training, relocation assistance, support for schools, housing and legal issues, expectations of Indian IT workers were unique. 
For the respondents in the current study, with lack of time prior to arriving along with expectations of them starting work straight after arrival, the issues were mainly around the time and basic logistical support to find accommodation in the initial period. This suggests that the perceptions of support from parent organizations of Indian IT workers are unique compared to traditional expatriates. In line with organization support theory, these IT workers spoke about not feeling valued or cared for by their organization (Eisenberger et al., 1986). This is due to their circumstances within the GDM. As one respondent noted:

In the initial days, it would be less burden on your work to get accommodation and to get your accommodation right and get a feel about the place before you get into your work. In the initial stage, the organization (parent Indian IT MNC) should play a part and in my case, I just came here and had to start work, so it was hard. (Mitesh/A)

Although most of the expatriates had not expected much from their parent organization, just a little assistance with the logistics and country orientation during the initial months could make the initial period much smoother; this in turn has implications for the HR function in the host country.

\subsubsection{Parent HR support in the host country and intention to stay or leave}

Indian IT MNCs' HR in the host country was viewed by most of the interviewees as a potentially important source of organizational support, as they considered them to be the representative of their "parent company". As pointed out by Kraimer et al. (2001), during the initial months the parent company is often the main source of support to help facilitate adjustment to work and the general environment. However, this is very different to our research findings, where there was a perceived lack of HR backing in the host country from the employer, yet the IT expatriates were expected to work under the Indian HR stated practices. As one expatriate explained: 
No HR support. We can reach them and ask them but the number of engagements is too large... Support system is there, HR people are there, but it is not as prominent. (Arun/B)

There was a view that while employees did have a parent HR department in India and perhaps an office subsidiary in Australia, it was pointless to approach these staff for assistance due to low ratios of HR personnel to employee staff and the high workloads in those HR departments. Some respondents also felt that HR was not approachable, or that they had very specific roles as a strategic partner to the MNC, which did not include assistance with the kind of problems that expatriate workers were experiencing in the host country. Consequently, employees were not comfortable asking for more help beyond those roles. One senior professional evaluated the role of HR at his Indian company's Australian office as follows:

I think there is an area of HR that needs to be improved on and the stability of HR is not as good as I could appreciate, as the HR manager has many different jobs to do. The area that needs improvement is that accessibility to someone where you can ask questions and have them answered. (Shravan/A)

These findings resonate with the HRM literature on the Indian IT sector, which argues that due to the large number of employees in the industry, HR is usually overworked and/or only doing the basic day-to-day work with its focus on recruitment and hiring in an industry that has been experiencing exponential growth (Agrawal et al., 2012; Budhwar and Khatri, 2001). Most interviewees indicated that they had expected their parent Indian MNCs' HR in Australia as a potentially important source of organizational support; however for most the reality was contradictory.

For example, due to a lack of support from the parent MNC HR, one female respondent stated that she approached the HR managers at the client site, who she found to be more 
helpful than HR in her own company:

If there was any problem, I called the HR at the client office, not at my company office, as I do not even know the HR at my office, as we hardly get to interact with them. One more disappointing factor is that when they organize meetings, they will organize them during business hours ... then they point out that there have been meetings but you did not come for them ... So I just contact my HR at the client site... when I was looking for the house I would check with her (client manager) and she helped me out and guided me but I did not get any support from my company. (Sudha/B)

Due to the nature of their work, many professionals noted that they do not have the liberty of approaching HR at a client site, as they are contract workers and are expected to sort any issues out with their employer.

As explained by one participant:

What is missing is a helping hand on the shoulder; not just our organization but all organizations across India. I am not sure if the fear is misuse... Most of the employees are without family, so the employers and colleagues are family here. (Ritesh/B )

This issue of limited preparation and inadequate support was a consistent theme; half of the participants interviewed advised that if they had another job offer they would leave their organization. Some participants noted:

I would definitely leave my organization to work with another company, as I do not feel valued here or a part of the organization. I am just seen as a resource and not as a human! (Shiv/D)

We are just resources here, they do not care about what work you do, and it's how much we can coax the client to bring in another person... (Sachin/E) 
I would definitely leave my organization... I did contact my manager offshore (and said) "seen you have thrown us here and after that we are not your concern, while we are there you think of us as resource but after we are moved here you don't even bother with us" (Ruchi/A)

These interviews indicate that there is a need for a helping hand or mentor at the host locations during the initial months of settling in, due to the pressures of their novel circumstances.

\section{Discussion}

While much has been written about the Indian IT sector and the GDM, the significant experiences of Indian IT expatriates at client sites and the associated IHRM practices of parent companies (Indian IT MNCs) have been largely ignored. The present study has tried to bridge this gap by examining Indian IT IHRM practices through the lens of work and life experiences of IT expatriates working at overseas' client sites. The interview findings suggest that there are issues with the expatriation practices of Indian IT MNCs in regards to preparation and in-country support, which impact on the experiences of IT workers. A key factor explaining our findings is the low-cost and client-centric nature of the GDM of the Indian IT MNCs which reduces the time available for pre-assignment and post-arrival preparation. This combined with deficient support systems in the host country and lack of planning results in many problems for the expatriates. This study has recognized that in line with POS theory, how IT expatriates perceive the organizational support practices of their Indian IT companies impacts on their adjustment; however, the support expected by the Indian IT expatriates was in many ways unique compared to traditional expatriate literature. While the Indian IT expatriates did not have high expectations from their parent IT MNCs, they did expect support for basic needs such as accommodation and initial country 
orientation, due to lack of time to organize themselves prior to and during the assignment. Moreover, due to lack of preparation and inconsistent expectations, participants experienced issues at work with regards to differences between home and host cultures as well as expectations from clients as they were viewed as contractors. While the framework by Black and colleagues (1991) with its embedded assumptions has been seen as fitting in well with the traditional western MNC models (Black et al., 1991; Caligiuri et al., 1998; Gupta et al., 2013), it may need amendment or indeed adjustment to fit this group of IT expatriates working within IT business models. In considering how to implement this model, there is a need to consider how we would use it within a larger industry context. While some of the elements from Black et al.'s (1991) model suit the Indian IT context, some important variations are required.

The model looks at organizational preparation and support from a single organization's perspective, thereby assuming that the organization that selects and prepares workers for the assignment is the same as the organization in the host country. It does not take into consideration the complexities of the low-cost and labor arbitrage issues within the GDM, where a parent company sends their IT expatriates to international client locations as contractors. Furthermore, while the model emphasizes the need for training and appropriate anticipatory adjustments that will make the actual adjustment in the new international setting easier and quicker, it assumes that the organizations will have control over when the expatriates leave for the assignment. Being client dependent means that the Indian IT MNCs do not have much control over when IT workers need to leave for assignments, which combined with the low-cost nature of the industry means that often organizations compromise on the preparation and support for IT workers, and undertake opportunistic and exploitative practices. Furthermore, lack of time prior to leaving and after arrival means that IT workers cannot undertake much preparation or support themselves. Thus the anticipatory 
adjustment factors of Black et al.'s (1991) model may need variations with regards to emphasis on linking selected professionals to expatriates already in the host locations who could be their informants during the early stages of the assignment. Within the in-country adjustment phase, some variations are needed. Some factors are more relevant within this industry than others, as identified in the current study. For instance, due to the expectation of IT expatriates starting work within a few days of arrival, the need for organizations to provide basic logistical support with regards to accommodation and supervisor support or mentoring at the host locations during the initial stages, is more pronounced. Moreover, the argument of individual socialization tactics of organizations and its association to adjustment will also need variations to suit this group. Whether the socialization of expatriates to the client organization is possible within this framework is uncertain. In the Indian IT sector, the dynamic interplay between IHRM and GDM that reflects low-cost labor and client-centricity within the value chain will impact on the adjustment of IT expatriates at client locations. More importantly, the complexities of IT expatriates working at international client locations under the HR practices of the parent Indian IT MNC are worthy of consideration within a IHRM framework.

\section{Conclusion and Implications}

Our research has examined issues of global outsourcing and internationalization within the Indian IT industry and the challenges that Indian IT expatriates at client sites experience within the larger scope of IHRM. The major contribution of this research is to provide an understanding of the expatriation practices of IT MNCs from an emerging market (India) from the perspective of IT worker expatriates going to a client site in a developed country. The interview findings with the Indian IT expatriates suggest that there are issues with the expatriation practices of Indian IT MNCs in regards to preparation and in-country support. 
However, the main issue identified was the GDM which was customer-centric and low-cost, with a high dependence on client contracts. From the analysis and findings, themes emerged that were recognized as critical in the experiences of Indian IT expatriates on an international assignment at client sites. One of the significant findings of this study is that due to large numbers of IT workers travelling overseas every week and limited personnel within HR there is a disconnect between the roles that HR is expected to perform and what actually transpires. It appears that lack of adequate planning has triggered this issue and this in turn influences IT expatriates' experiences in the host country.

The IHRM expatriation and adjustment literature has mainly focused on western managers. The current research has worked to bridge the gap by studying a different kind of employee (IT contract workers) and a different context for expatriation (the emerging market of India) and presented a variation to Black et al.'s (1991) framework to cater to this industry. While previous studies have mainly looked at managerial expatriates, the current research has examined the perspective of skilled IT workers. Moreover, most of the IHRM research and adjustment literature has focused on expatriate managers going to work in subsidiary offices from either a developed country to a developed country or from developed country to a developing country. This research provides an alternative but increasingly relevant view of expatriation and recommendations for a framework better suited to this cohort and industry. Our analysis shows that subject to a different, and in some ways unique, business model, new demands are placed on the HR function. In the case of those who participated in this study, these HR demands are only partially being met and this again is a consequence of the dynamics entailed in the GDM of the IT industry. This model provides opportunities for human resource development as well as temptations to engage in opportunistic practices, as the testimonies presented here make clear.

Like all research, this study has its limitations. The primary limitation is that data was 
collected from participants at a particular point of time during the assignment. Future research may adapt a longitudinal design which would provide an understanding of whether or not pre-departure preparation and in-country support practices influence the adjustment experiences and the expatriates' perceptions of the organizational support over time. The research focuses on IT expatriates from one emerging market, India; therefore, future research may extend to samples from other Asian MNCs and EMNCs and their expatriates, and compare IHRM practices of the MNCs across countries. Furthermore the data was collected from IT expatriates who stayed on the assignment; the ones who might have returned early from their assignment or terminated their employment early were not included in the study. Future research may also interview expatriates who left their organizations in order to compare the experiences of both groups.

\section{Reference list}

Agrawal, N.M., Khatri, N., Srinivasan, R., 2012. Managing growth: Human resource management challenges facing the Indian software industry. Journal of World Business 47, 159-166.

Agrawal, N.M., Thite, M., 2006. Nature and importance of soft skills in software project leaders. Asia Pacific Management Review 11, 405-413.

Agrawal, N.M., Thite, M., 2003. Human resource issues, challenges and strategies in the Indian software industry. International Journal of Human Resources Development and Management 3, 249-264.

Ashford, S., Taylor, S., 1990. Understanding individual adaptation: An integrative approach. In: Rowland, K., Ferris, J. (Eds.), Research in Personnel and Human Resource Management. JAI Press, Greenwich, CT, pp. 1-39. 
Bazeley, P., Richards, L., 2000. The NVivo Qualitative Project Book. Sage, Thousand Oaks, CA.

Bhaskar-Shrinivas, P., Harrison, D.A., Shaffer, M., Luk, D.M., 2005. Input-based and timebased models of international adjustment: Meta-analytic evidence and theoretical extensions. Academy of Management Journal 48, 257-281.

Bhatnagar, S., Madon, S., 1997. The Indian software industry: Moving towards maturity. Journal of Information Technology 12, 277-288.

Birur, S., Muthiah, K., 2012. Knowledge transfer from repatriated employees: The Indian experience. The IUP Journal of Knowledge Management 10 (1), 7-25.

Black, J., Mendenhall, M., Oddou, G., 1991. Toward a comprehensive model of international adjustment: An integration of multiple theoretical perspectives. Academy of Management Review 16, 291-317.

Budhwar, P., 2004. Managing Human Resources in Asia-Pacific. Routledge, London.

Budhwar, P., Khatri, N., 2001. HRM in context: Applicability of HRM models in India. International Journal of Cross Cultural Management 1, 333-356.

Budhwar, P., Luthar, H., Bhatnagar, J., 2006. Dynamics of HRM systems in BPOs operating in India. Journal of Labor Research XXVII (3), 339-360.

Budhwar, P., Sparrow, P., 2002. Strategic HRM through the cultural looking glass: Mapping cognitions of British and Indian HRM managers. Organization Studies 23, 599-638.

Budhwar, P., Sparrow, P., 1997. Evaluating levels of strategic integration and devolvement of human resource management in India. The International Journal of Human Resource Management 8, 476-494. 
Caligiuri, P., Hyland, M.M., Joshi, A., Bross, A.S., 1998. Testing a theoretical model for examining the relationship between family adjustment and expatriate's work adjustment. Journal of Applied Psychology 83, 598-614.

Caligiuri, P., Phillips, J., Lazarova, M., Tarique, I., Burgi, P., 2001. The theory of met expectations applied to expatriate adjustment: The role of cross-cultural training. International Journal of Human Resource Management 12 (3), 357-372.

Collings, D., Scullion, H., 2006. Global staffing. In: Stahl, G.K., Björkman, I. (Eds), Handbook of Research in International Human Resource Management. Edward Elgar, Cheltenham, UK, pp. 141-157.

Crotty, M., 1998. The Foundations of Social Research: Meaning and Perspective in the Research Process. Allen and Unwin, St. Leonards.

Denzin, N.K., Lincoln, Y.S., 2011. Sage Handbook of Qualitative Research, 4 ed. Sage Publications, Thousand Oaks.

Doh, J.P., 2005. Offshore outsourcing: Implications for international business and strategic management theory and practice. Journal of Management Studies 42, 695-704.

Eisenberger, R., Armeli, S., Rexwinkel, B., Lynch, P., 2001. Reciprocation of perceived organizational support. Journal of Applied Psychology 86 (1), 42-51.

Eisenberger, R., Huntington, R., Hutchinson, S., Sowa, D., 1986. Perceived organizational support. Journal of Applied Psychology 71 (3), 500-507.

Eisenhardt, K.M., 1989. Building theories from case study research. Academy of Management Review 15, 535-550.

Feuerstein, P., 2013. Patterns of work reorganization in the course of the IT industry's internationalization. Competition and Change 17 (1), 24-40. 
Fisher, C.D., 1985. Social support and adjustment to work: A longitudinal study. Journal of Management 11, 39-53.

Flecker, J., Meil, P., 2010. Organisational restructuring and emerging service value chains — Implications for work and employment. Work, Employment and Society 24 (1), 119.

Gereffi, G., 2001. Shifting governance structures in global commodity chains, with special reference to the Internet. American Behavioral Scientist 44, 1616-1637.

Gregersen, H., Black, J., 1990. A multifaceted approach to expatriate retention in international assignments. Group and Organizational Management 15, 461-485.

Gupta, B., Singh, D., Jandhyala, K., Bhatt, S., 2013. Self-monitoring, cultural training and prior international work experience as predictors of cultural intelligence — A study of Indian expatriates. Organizations and Markets in Emerging Economies 4 (1), 56-71.

Guzzo, R., Noonan, K., Elron, E., 1994. Expatriate managers and the psychological contract. Journal of Applied Psychology 79, 617-626.

Haslberger, A., Brewster, C. Hippler, T., 2014. Managing Performance Abroad: A New Model for Understanding Expatriate Adjustment. Routledge, London.

Hechanova, R., Beehr, T.A., Christiansen, N.D., 2003. Antecedents and consequences of employees' adjustment to overseas assignment: A meta-analytic review. Applied Psychology 52, 213-236.

Jiang, J.J., Klein, G., 2002. A discrepancy model of information system personnel turnover. Journal of Management Information Systems 19, 249-272.

Kahumuza, J., Schlechter, A.F., 2008. Examining the direct and some mediated relationships between perceived support and intention to quit. Management Dynamics $17(3), 2-19$. 
Kawai, N., Strange, R., 2014. Perceived organisational support and expatriate performance: Understanding a mediated model. The International Journal of Human Resource Management 25 (17), 2438-2462.

Kraimer, M.L., Wayne, S.J., 2004. An examination of perceived organizational support as a multidimensional construct in the context of an expatriate assignment. Journal of Management 30 (2), 209-237.

Kraimer, M.L., Wayne, S.J., Jaworski, R.A., 2001. Sources of support and expatriate performance: The mediating role of expatriate adjustment. Personnel Psychology 54 (1), 71-99.

Lakha, S., 2009. Difference in transnational organization in Australia: The case of transient Indian Information Technology (IT) professionals. In: Gillian, M., Pokrant, B. (Eds.), Trade, Labour and Transformation of Community in Asia. Palgrave Macmillan, Basingstoke, pp.234-257.

Levy, D., 2005. Offshoring in the new global political economy. Journal of Management Studies 42 (3), 685-93.

Maertz, C.P., Griffeth, R.W., Campbell, N.S., Allen, D.G., 2007. The effects of perceived organizational support and perceived supervisor support on employee turnover. Journal of Organizational Behavior 28, 1059-1134.

Manning, S., Larsen, M.M., Bharati, P., 2015. Global delivery models: The role of talent, speed and time zones in the global outsourcing industry. Journal of International Business Studies 46 (7), 850-877.

Manning, S., Massini, S., Lewin, A.Y., 2008. A dynamic perspective on next-generation offshoring: The global sourcing of science and engineering talent. Academy of Management Perspectives 22 (3), 35-54. 
Mathew, J., Ogbonna, E., Harris, L., 2012.Culture, employee work outcomes and performance: An empirical analysis of Indian software firms. Journal of World Business 47, 194-203.

Morley, M., Collings, D., 2004. Contemporary debates and new directions in HRM in MNCs. International Journal of Manpower 25 (6), 487-559

Nanda, R., Khanna, T., 2010. Diasporas and domestic entrepreneurs: Evidence from the Indian software industry. Journal of Economics and Management Strategy 19, 9911012.

NASSCOM (National Association of Software and Services Companies). 2015. Indian ITBPO Industry/ IT Services (retrieved March 23, 2016 at http://www.nasscom.in/itservices).

Patton, M.Q., 2008. Utilization-Focused Evaluation, 4 ed. Sage Publications, Thousand Oaks, CA.

Patton, M.Q., 2002. Qualitative Research \& Evaluation Methods, 3 ed. Sage Publications, Thousand Oaks: CA.

Reiche, B.S., Kraimer, M.L., Harzing, A.W., 2011. Why do international assignees stay? An organizational embeddedness perspective. Journal of International Business Studies $42(4), 521-544$.

Richards, L., 2009. Handling Qualitative Data: A Practical Guide, 2 ed. Sage Publications, London.

Ritchie, J., Lewis, J., 2003. Qualitative Research Practice: A Guide for Social Science Students and Researchers. Sage Publications, London.

Russell, B., 2009. Smiling Down the Line: Info-Service Work in the Global Economy. University of Toronto Press, Toronto, ON. 
Scullion, H., Collings, D.G., Gunnigle, P., 2007. International HRM in the 21st century: Emerging themes and contemporary debates. Human Resource Management Journal 17, 309-319.

Selwyn, B., 2013. Social upgrading in global production networks: A critique and an alternative conception. Competition and Change 17, 75-90.

Shaffer, M., Harrison, D.A., Gilley, K.M., 1999. Dimensions, determinants, and differences in the expatriate adjustment process. Journal of International Business Studies 30, 557581.

Sharma, A., Loh, P., 2009. Emerging trends in sourcing of business services. Business Process Management Journal 15, 149-165.

Sirmon, D.G., Gove, S., Hitt, M.A., 2008. Resource management in dyadic competitive rivalry: The effects of resource bundling and deployment. Academy of Management Journal 51, 918-935.

Strubler, D., Park, S.H., Agarwal, A., 2011. Revisiting Black, Mendenall, and Oddou (1991)'s framework for international adjustment model: A prescriptive approach. Journal of International Business Research 10 (2), 103-120.

Sudhakar, G.P., Farooq, A., Patnaik., 2011. Soft factors affecting the performance of software development teams. Team Performance Management: An International Journal 17 (3/4), 187-205.

Takeuchi, R., Wang, M., Marinova, S., Yao, X., 2009. Role of domain-specific facets of perceived organizational support during expatriation and implications for performance. Organization Science 20 (3), 621-634. 
Thite, M., Budhwar, P. Wilkinson, A., 2014. Global HR roles and factors influencing their development: Evidence from emerging Indian IT services multinationals. Human Resource Management 53, 921-946.

Thite, M., Wilkinson, A., Shah, D., 2012. Internationalization and HRM strategies across subsidiaries in multinational corporations from emerging economies - A conceptual framework. Journal of World Business 47, 251-258.

Tung, R.L., 1987. Expatriate assignments: Enhancing success and minimising failure. Academy of Management Executive 1 (2),117-126.

Upadhya, C., 2009. Controlling offshore knowledge workers: Power and agency in India's software outsourcing industry. New Technology, Work, and Employment 24 (1), 2-18.

Upadhya, C., Vasavi, A., 2006. Work, culture and sociality in the Indian Information Technology (IT) industry: A sociological study. Project Report, National Institute of Advanced Studies, Bangalore.

Vallabh, G., Mishra, S., Bhatia, A., 2008. Analysis of onsite/offshore cost control model for Indian IT Majors. Management Accountant 43 (3), 143-148.

Varma, A., Budhwar, P., 2012. International human resource management in the Indian context. Journal of World Business 47, 157-158.

Walliman, N., 2006. Social Research Methods. Sage Publications, London.

Wang, M., Takeuchi, R., 2007. The role of goal orientation during expatriation: A crosssectional and longitudinal investigation. Journal of Applied Psychology 92, 1437-1445.

Witte, R., Witte, J., 2004. Statistics. Wiley, Hoboken, NJ.

Wolcott, H. 1999. Ethnography: A Way of Seeing. AltaMira Press, Walnut Creek, CA. 
Woodard, M., Sherman, K., 2015. Toward a more complete understanding of offshoring: Bringing employees into the conversation. The International Journal of Human Resource Management 26, 2019-2038.

Wu, P.C., Ang, S.H. 2011. The impact of expatriate supporting practices and cultural intelligence on cross-cultural adjustment and performance of expatriates in Singapore. International Journal of Human Resource Management 22, 2683-2702. 


\section{Table 1: Interview Guide}

\section{Demographics: Name/ Age/ Marital Status/ Tenure/ Organization/Level Within the Organization/ Years on the}

Assignment/ Time and Length on Current Assignment

Can you please advise the reason for the international assignment? How did the assignment arise? In brief, can you please explain your parent companies business model and their main business in Australia?

Could you explain the selection process for your assignment?

What were the main reasons for you to accept this international assignment?

Once being selected for this assignment, how much time were you given to prepare prior to leaving for the assignment? Did you feel that it was sufficient time for you to prepare for the assignment?

Did you receive any form of pre-departure preparation from your organization? Did you find it relevant and useful? Do you believe that it helped you with setting accurate expectations for the assignment?

Did your organization provide any support systems on your arrival into Australia? What form did it take? Did you think that was enough?

Did you have other support systems in place in Australia?

- HR of your parent organization

- Other colleagues already on the assignment

- Friends or relatives?

What were the main issues that you felt were difficult in the adjustment process?

- How did you overcome these?

- Did your company or HR play a part in helping you overcome these difficulties? Do you believe your organization should have played a part in helping with the adjustment process? How do you perceive the support you received?

What factors made your adjustment into the new environment easier?

Overall, how satisfied are you with the method in which the international assignment is managed?

If given an opportunity to work with a local Australian company, would you consider switching your job? 